\title{
Impact of COVID-19 on the Economic Output of the US Outbreak's Epicenter
}

\author{
Orkideh Gharehgozli $^{1}$ (D) Peyman Nayebvali ${ }^{2} \cdot$ Amir Gharehgozli $^{3}$. \\ Zaman Zamanian ${ }^{4}$
}

Received: 17 May 2020 / Accepted: 14 July 2020 / Published online: 21 July 2020

(C) Springer Nature Switzerland AG 2020

\begin{abstract}
Coronavirus disease of 2019 (COVID-19) started in December 2019 in Wuhan, China. In a few months, it has become a pandemic with devastating consequences for the global economy. By the end of June, with almost 2.6 million confirmed COVID-19 cases, United States is above other countries in the rankings. Furthermore, New York with more than 416 thousand cases is the epicenter of outbreak in the US and had more cases than any other countries in the world until first half of June. In this paper, we use a two-step Vector Auto Regressive (VAR) model to forecast the effect of the virus outbreak on the economic output of the New York state. In our model, we forecast the effect of the shutdown on New York's Gross Domestic Product (GDP) working with Unemployment Insurance Claim series representing a workforce factor, as well as the Metropolitan Transportation Authority (MTA) ridership data indicating the economic activity. We predict annualized quarterly growth rate of real GDP to be between -3.99 to $-4.299 \%$ for the first quarter and between -19.79 to $-21.67 \%$ for the second quarter of 2020.
\end{abstract}

This article is part of the Topical Collection on Economics of COVID-19

Orkideh Gharehgozli

gharehgozlio@montclair.edu

Peyman Nayebvali

pn2202@columbia.edu

Amir Gharehgozli

amir.gharehgozli@csun.edu

Zaman Zamanian

zamanianz@montclair.edu

1 Department of Economics, Feliciano School of Business, Montclair State University, 1 Normal Avenue, Montclair, NJ 07043, USA

2 Department of Industrial Engineering and Operations Research, Columbia University, New York, NY, USA

3 Nazarian College of Business and Economics, California State University, Northridge, CA, USA

4 Department of Economics, Feliciano School of Business, Montclair State University, Montclair, NJ, USA 
Keywords Forecast - Time series - Vector auto regressive - Gross domestic product . Unemployment insurance claim · COVID-19

\section{Introduction}

The year 2020 started with the outbreak of Coronavirus disease of 2019 (COVID-19), prompted by a virus belonging to the family of Coronaviruses, namely severe acute respiratory syndrome coronavirus 2 (SARS-CoV-2) (AE Gorbalenya et al. 2020). It was first diagnosed, as a atypical case of pneumonia, in Wuhan, China in December 2019 and since then it has become a pandemic, spreading to all around the world.

Although since the outbreak in December 2019 until March 6, 2020, it took a few months to get to 100,000 confirmed COVID-19 cases around the globe, but the number of cases has doubled every few days in March (World Health Organization (WHO) 2020). Such an increase has occurred despite multiple measures such as social distancing (also called physical distancing), telework, closed schools and universities, quarantine of cities, cancellation of sports events, cruises, festivals, and other gatherings that governments in many countries have prompted. As of June, 2020, globally, there has been more than 10.23 million confirmed COVID-19 cases with more than 500,000 deaths (World Health Organization (WHO) 2020).

In the beginning, the spread of COVID-19 was not a serious concern in the United States. However, the situation suddenly escalated and the number of confirmed COVID-19 cases and deaths suddenly boomed and rose above other countries. According to the (Centers for Disease Control and Prevention (CDC) 2020), in January 14, 2020, the number of confirmed COVID-19 cases in the US was only 3 cases, whereas in the middle of April, it suddenly jumped to more than 520,000 cases, and it is 2,632,656 as of June 28.

New York with highest number of confirmed cases has been the epicenter of COVID-19 in the US. The numbers of confirmed cases and deaths in New York state alone currently are the fifth highest among all other the countries (and had been the highest up until early June). It all started on March 1, 2020, when the first confirmed case in New York was announced. Since then until June 28, 2020, the number of confirmed COVID-19 cases has increased to 416,769 cases. This is despite multiple protective measures against the new Coronavirus enforced in New York. The measures range from declaring a state of emergency, to closing schools, restricting mass gatherings, and issuing Stay-At-Home Coronavirus Order for the entire New York state.

COVID-19 has caused severe negative consequences for the economy of the US and New York by disrupting and introducing risks and vulnerabilities. According to the (US Department of Labor ), the Weekly Unemployment Insurance Claims have increased to a peak of more than 6.2 million Seasonally Adjusted Initial Claims in the week ending April 4, 2020. The same data in the comparable week in 2019 shows that there were 203,000 Seasonally Adjusted Initial Claims. In New York, for the last week of March number of new claims was reported to be 366,595 , followed by 344,451 new claims in the week ending April 4, 2020, and the peak happened in the second week of April; a week with 394,701 new cases. The total number of New Yorkers filing new jobless claims has surpassed 1.7 million by the end of April. Such numbers shows the severity of COVID-19 and the impacts on New York's economy. The very high level of jobless claims is more than $4 / 5$ of the total jobless claims filed during the entire time of the Great Recession in June 2007-November 2009.

It is specially important to study and aim to understand the economic consequences of the outbreak and the shutdown during this period of time, as any information as such plays 
a critical role in the decision making processes such as "reopening" policies and timelines. The Bureau of Economic Analysis (BEA) uses official service surveys as well as goods sector survey (which are delayed and less frequent) to estimate GDP. The most timely service sector activity within the BEA's national income and product accounts (NIPA) comes from the Quarterly Services Survey, which is unavailable for the Advanced GDP release, and in lieu of this data the staff at the BEA estimates services GDP based on a judgmental trend. In all likelihood we will not know the full extent of the economic damage until the 2020 benchmark revisions are released in June-2021. So we believe studies that pay attention to the economic effects of the outbreak can be essential during this period of time. Many studies have aimed to provide better understanding of the economic aspects of the lock-downs from different point of view ever-since the outbreak started. Mandel and Veetil (2020) take a supple chain point of view and work with a multi-sector disequilibrium model with buyer-seller relations between agents located in different countries; and using the World Input-Output Table they calibrate their model to the world economy involving 56 sectors in 44 countries. They conclude that world output falls by $7 \%$ at the early stage of the crisis when only China is under lock-down and by $23 \%$ at the peak of the crisis when many countries are under a lock-down. From a similar point of view (Pichler et al. 2020) analyse the economics and epidemiology of different scenarios for a phased restart of the UK economy. They investigate six different re-opening scenarios, presenting their best estimates for the increase in GDP.

In a more related study, Wang et al. (2020) work with a VAR model and analyse the effect of COVID-19 on the quarterly output of China, working with the daily railway passenger volume data during the Spring Festival travel rush as an exogenous variable, and establish three time series to model the railway passenger volume, GDP in the first quarter model, and GDP in the last three quarters respectively. The VAR model, which enables us to capture the co-variation of economic/financial variables and to utilize it to forecast an outcome variable of interest or to measure the responses of each outcome variable to exogenous shocks, is a very popular among researchers specifically those exploring aggregated macro economic variables (Berisha 2020; Aviral and et al 2011; Narayan et al. 2008; Hatemi-J 2014; Giordano et al. 2007). In this paper, we use a two-step forecast model to study the impact of COVID-19 on New York's economic output; Gross Domestic Product (GDP). In our model, the weekly Unemployment Insurance Claims is one of the variables. Furthermore, following (Wang et al. 2020), the second variable is the total weekly Metropolitan Transportation Authority (MTA) card swipes. Although MTA is not the only transportation medium in the state of New York, but by serving a population of 15.3 million people in the New York metropolitan area, MTA is the largest transportation network in North America and is one of the main transport modes to get to workplace. In the beginning of the outbreak, there were plans to shut down the network. However, being one of the main means of transportation, the plans were never implemented. So in our model we use the ridership to help us capture and present economic activity.

The detail of our proposed two-step model is as follows. In the first step, we forecast the effect of the COVID-19 on New York's workforce. We use a series of weekly Unemployment Insurance Claims as a representative of the work-force condition in a Vector Auto Regressive (VAR) model, along with a series of total weekly Metropolitan Transportation Authority (MTA) card swipes representing economic activities. The highly continuous (negative) co-variation of these two series over a long period of time, incorporated in a VAR model which captures such variation of economic time series, enhances our ability to more precisely estimate and measure the magnitude of the shocks these series have encountered recently. In the first stage, we work with the weekly data to have a higher precision as the circumstances have changed rapidly and over a short period of time. Following, using the 
weekly forecast values we measure the quarterly magnitude of the downfall in the workforce employment since the outbreak. Next, in the second step, we use a VAR model this time with quarterly data and we estimate the response of the GDP with respect to the overall employment shock we measure from the first step.

The rest of this paper is structured as follows. Section "Sample and Data" introduces the data and sources. Section "2-Step VAR Model" presents the model and discusses the findings and insights. Last section concludes the paper.

\section{Sample and Data}

We look at the Office of Unemployment Insurance Weekly Claims Report, provided by the United States Department of Labor, Employment and Training Administration (US Department of Labor ). The data ranges from $01 / 03 / 1987$ (the first week of January 1987) to $06 / 20 / 2020$ (the $25^{\text {th }}$ week of the year).

For the transportation data, we look at MTA Fare data (MTA ). The Metropolitan Transportation Authority is North America's largest transportation network (serving a population of 15.3 million people) across a 5,000-square-mile travel area surrounding New York City through Long Island, southeastern New York State, and Connecticut. MTA provides weekly update on the number of number of MetroCard swipes made each week by customers entering each station of the New York City Subway, PATH, AirTrain JFK and the Roosevelt Island Tram, broken out to show the relative popularity of the various types of MetroCards. MTA New York City Transit posts the latest data every Saturday by 1 A.M.. The data in the files covers seven-day periods beginning on the Saturday two weeks prior to the posting date and ending on the following Friday.

For the GDP data, we use U.S Department of Commerce data (Bureau of Economic Analysis ) available at the state-level ending in the last quarter of 2019.

\section{2-Step VAR Model}

In this section, we provide the two-step VAR model and discuss our findings. The first step of the model is discussed in "Step 1: Forecast of the Weekly Unemployment Insurance Claims", where we estimate the magnitude of the effect of COVID-19 on the Unemployment Insurance Claims. The second step is discussed in "Step 2: Forecast of the Economic Output Along with the Unemployment Insurance Claims", where we estimate the response of the quarterly GDP using the findings of the previous section.

\section{Step 1: Forecast of the Weekly Unemployment Insurance Claims}

First, the top panel of Fig. 1 presents the Weekly Unemployment Insurance Claims (WUIC) as well as the Weekly "MTA Swipes" over the period 2010 to the $25^{\text {th }}$ week of 2020 to depict the behavior of the series and to provide the magnitude of the shocks. To have a clearer presentation of the co-variation of the two series before the shocks, in the bottom panel we zoom in and provide the two series for the period 2010 to the $11^{\text {th }}$ week of 2020 .

By the end of the last week of March, total MTA metro card swipes fell by $85.7 \%$ compared to the week before the shock (which is equivalent of 8.3 times the standard deviation). With respect to the Unemployment Insurance Claims, as mentioned earlier the peak of 394,701 new weekly claims happened in the second week of April. No other shock of 

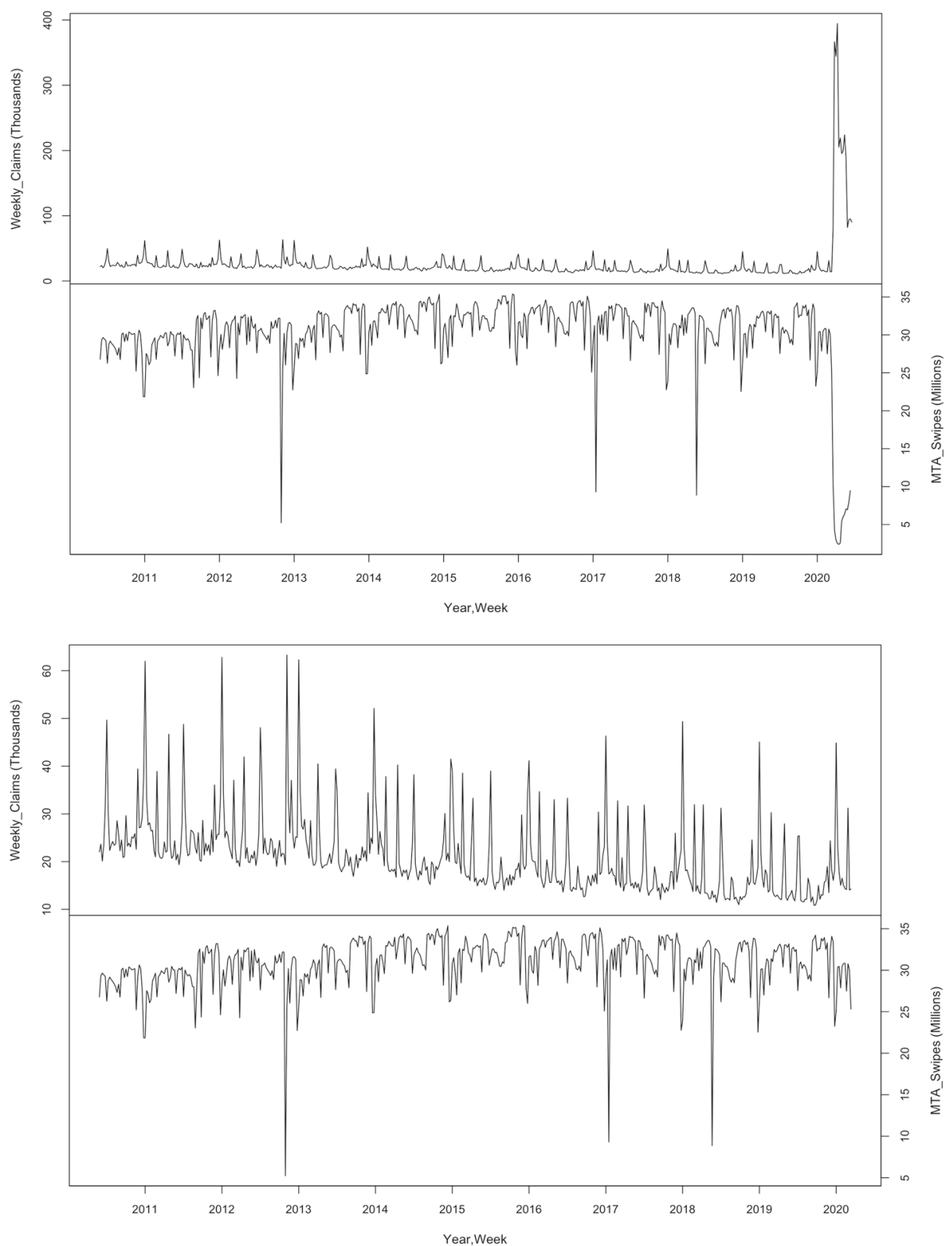

Fig. 1 Weekly Unemployment Insurance Claims and Total Weekly MTA Ridership; Top Panel: 2010-W22 to 2020-W25, Bottom Panel: 2010-W22 to 2020-W11

such magnitude is observed in the insurance claim series over the period of our analysis. As can be seen in Fig. 1, there are three other MTA ridership shocks earlier over the period of analysis two of which (dated on November 2012 and January 2017) are synchronous with positive (and less dramatic) unemployment shocks and are happening in the months with 
usually lower ridership and possibly more laid off employees. The last one is in June 2018 and seems not to be correlated with higher insurance claims. ${ }^{1}$.

We consider the seasonality on our VAR model but before that, we look at the stationary and the auto-correlation of our data and we provide the results in Table 1. We look at the Phillips-Perron test (Phillips and Perron 1988), and the Dickey-Fuller and Augmented Dickey-Fuller tests (Said and Dickey 1984) which performs better in finite samples (Davidson et al. 2004). The results of the tests conclude that the series are stationary and not following a white noise process. The suggested "order of differencing" to obtain stationary series in our analysis is zero ${ }^{2}$.

In our VAR model we perform :

$$
\left\{\begin{array}{l}
W U I C_{t}=\alpha_{1}+\beta_{1 t}+\rho_{11} W U I C_{t-1}+\ldots+\rho_{1 k} W U I C_{t-k}+\theta_{11} M T A S_{t-1}+\ldots+\theta_{1 k} M T A S_{t-k}+v_{1 t} \\
M T A S_{t}=\alpha_{2}+\beta_{2 t}+\theta_{21} M T A S_{t-1}+\ldots+\theta_{2 k} M T A S_{t-k}+\rho_{21} W U I C_{t-1}+\ldots+\rho_{2 k} W U I C_{t-k}+v_{2 t}
\end{array}\right.
$$

where WUIC and MTAS are Weekly Unemployment Insurance Claims and Weekly MTA Swipes, $\rho_{11, \ldots, 1 k}$ are the coefficients of lagged terms of WUIC in the WUIC equation, $\rho_{21, \ldots, 2 k}$ are the coefficients of lagged terms of WUIC in the MTAS equation, $\theta_{11, \ldots, 1 k}$ are the coefficients of lagged terms of MTAS in the WUIC equation, $\theta_{21, \ldots, 2 k}$ are the coefficients of lagged terms of MTAS in the MTAS equation, $\alpha$ is the intercept, and $\beta_{1 t}$ and $\beta_{2 t}$ are time trends. $v_{1 t}$ and $v_{1 t}$ are the error terms (assumed to have mean zero and no serialcorrelation). AIC recommends the number of lags to consider in our model to be 10 . We also consider seasonality of both series in our VAR specification. We test for auto-correlation in

\footnotetext{
${ }^{1}$ From our data depicted in Fig. 1, we observe the 2012 and 2017 shocks are following the direction of the seasonality of the data, and lower MTA ridership is also synchronous with higher unemployment. Moreover, New York State Department of Labor has information about "Monthly Mass Layoffs" (which is different than the Unemployment Insurance Claims data) for 2008 t0 2013. In attempt to find explanations, we confirmed that the number of mass layoffs ("A potential mass layoff event occurs when at least 50 initial claims are filed against an UI number during a consecutive 5-week period") is abnormally high in Nov 2012, the month of January for all these available years: https://labor.ny.gov/stats/mlsnysm.shtm. The 2012 shock in the MTA ridership can be explained by the hurricane Sandy that hit the whole state of New York in November 2012 and caused major shutdowns in the transportation system and possibly major layoffs and higher insurance claims. But we can not find such explanation for the other 2 events.

${ }^{2}$ The Dicky-fuller test is testing if $\phi=1$ in the model below (which would mean we have a random walk process):

$$
Y_{t}=\alpha+\beta * t+\phi Y_{t-1}+e_{t}
$$

which is equivalent of testing if $\gamma=0$ in

$$
\Delta Y_{t}=Y_{t}-Y_{t-1}=\alpha+\beta * t+\gamma \Delta Y_{t-1}+e_{t}
$$

where $Y$ is either one of our series (WUIC or MTAS). The Augmented Dickey-Fuller test allows for higherorder auto-regressive processes meaning it is testing if $\gamma=0$ in

$$
\Delta Y_{t}=Y_{t}-Y_{t-1}=\alpha+\beta * t+\gamma \Delta Y_{t-1}+\delta_{1} \Delta Y_{t-1}+\delta_{2} \Delta Y_{t-2}+\ldots+e_{t}
$$

The null hypothesis for both tests is that the data are non-stationary. We want to reject the null hypothesis for this test, so we want a p-value of less that 0.05 (or smaller). For a DF test we can set K (the number of $\delta$ lags) to zero. The default number of included lags for an Augmented DF test is calculated from trunc $(($ Length $(Y)-$ $\left.1)^{(1 / 3)}\right)$. For our data, the length of both series is 511 which is why the number of lags included in the ADF test is 7. Both DF and ADF tests P-values rejected the null of $\gamma=0$ which means the series are stationary. Note that in DF and ADF tests, the regression includes drift and trend parameters. For the Phillips-Perron test (PP test) which builds on the DF test, also our specification includes drift and trend parameters. We use the "short" number for the truncation lag parameter which is set to $\operatorname{trunc}\left(4 *(\operatorname{Length}(Y) / 100)^{0.25}\right)$ (otherwise $\left.\operatorname{trunc}\left(12 *(\operatorname{Length}(Y) / 100)^{0.25}\right)\right)$. That is why the number of lags included in our PP test is 6 . The lag length in the LB test is 10 .
} 
Table 1 Stationary and white noise tests

\begin{tabular}{llll}
\hline & PP Test & DF test & ADF test \\
\hline WUIC & $-360.87^{* * *}$ & $-16.846^{* * *}$ & $-5.7523^{* * *}$ \\
& $(<0.01)$ & $(<0.01)$ & $(<0.01)$ \\
MTA-Swipes & $-405.31^{* * *}$ & $-16.252^{* * *}$ & $-5.147^{* * *}$ \\
& $(<0.01)$ & $(<0.01)$ & $(<0.01)$ \\
& & & Ljung-Box Test \\
WUIC & & $378.39^{* * *}$ \\
& & & $(<2.2 \mathrm{e}-16)$ \\
MTA-Swipes & & $174.36^{* * *}$ \\
& & & $(<2.2 \mathrm{e}-16)$ \\
\hline
\end{tabular}

Note: The number in paranthesis is the reported P-value of each statistic. The null hypothesis of the PhillipsPerron test and the Augmented Dickey-Fuller test is the series are non-stationary. The null hypothesis of the Ljung-Box test is the series are not auto-correlated.

${ }^{*} p<0.10,{ }^{* *} p<0.05,{ }^{* * *} p<0.01$

VAR errors using a Portmanteau test. The result is no auto-correlation in the residual of the VAR model ( $p$-value $=0.6106$ ).

Although at this stage we aim to utilize the VAR model to forecast the "normal" values of the WUIC series, in our analysis we inspect the Impulse Response Function of the WUIC to one standard deviation positive shock to the Weekly MTA Swipes and we observe the response is significant. Also importantly, the result of the Granger causality test (Granger 1969) is as follows; both Weekly MTA Swipes and Weekly Unemployment Insurance Claims Granger cause the other, and their lagged terms are jointly significant.

$\left(\begin{array}{lll}\text { WUIC } & \underline{W U I C} & \underline{M T A S} \\ M T A S & 2.2 e-16 & 0.004397\end{array}\right)$

Figure 2 below provides the forecast values of WUIC and MTAS driven from the VAR model. We use the data from $22^{\text {th }}$ week of 2010 ( the first week when MTA ridership data is available) to the $11^{\text {th }}$ week of 2020 (the starting week of the shocks) to train the model and we drive the forecast values of the series for the rest of 2020, although we only use the forecast values for the second quarter.

To recapitulate our analysis for the first and second quarter, by the end of the third week of March the actual value of the newly filed insurance claims jumps to 80,334 from the previous week's number of 14,272, followed by a big shock of 366,595 number of new claims filed by the end of the last week of March. We compare these values with the forecast values ("normal values") of the series driven from the VAR model (depicted in Fig. 2) and calculate the discrepancy. For the first quarter of 2020, the average weekly shock is calculated to be 35,137 claims. which is 4.32 times the standard deviation of the series (8141.9). Entering the second quarter, another 344,451 number of new claims were filed by the end of the first week of April. The peak has happened in the second week of April, the week with 394,701 number of new claims. For the second quarter, the average weekly shock is calculated to be 122,443 which is 15.04 times the standard deviation.

Next, in the second step we use study the relationship between the economic output (GDP) and the Unemployment Insurance Claims, and we study the response of the 


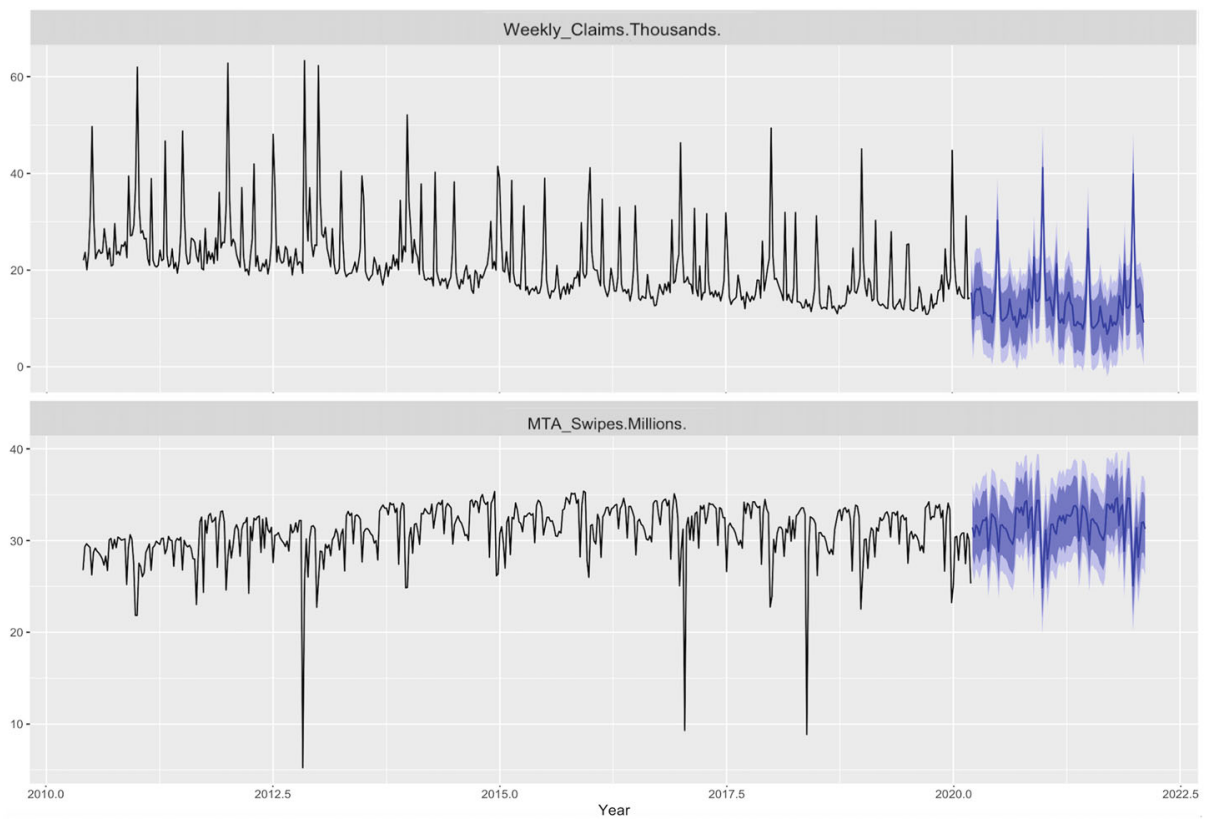

Fig. 2 VAR Forecast Path of the Weekly Unemployment Insurance Claims and Total Weekly MTA Swipes. First week is 2010-W22. (.5) Refers to Middle Week of the year

GDP to the negative shocks experienced by the workforce which we estimated from this step.

\section{Step 2: Forecast of the Economic Output Along with the Unemployment Insurance Claims}

In this step, we perform a VAR model working with quarterly GDP (GDP) (in Millions of chained 2009 dollars) and Quarterly Unemployment Insurance Claims(QUIC). We measure the Response Function of GDP to a shock in QUIC with the size of one standard deviation and we forecast the values of QGDP. Note that from the first step we measured the magnitude of the Insurance Claims shocks in the first and second quarters of 2020.

The quarterly data provided in Fig. 3 clearly shows seasonality and trend. In our second step VAR model, we decompose our series to employ de-seasoned and de-trended series in the VAR model. The result of our pre-VAR tests for the de-seasoned and de-trended series are provided in Table $2^{3}$.

In the second step, in our VAR model we perform :

$\left\{\begin{array}{l}Q U I C_{t}=\alpha_{1}+\rho_{11} Q U I C_{t-1}+\ldots+\rho_{1 k} Q U I C_{t-k}+\theta_{11} G D P_{t-1}+\ldots+\theta_{1 k} G D P_{t-k}+v_{1 t} \\ G D P_{t}=\alpha_{2}+\theta_{21} G D P_{t-1}+\ldots+\theta_{2 k} G D P_{t-k}+\rho_{21} Q U I C_{t-1}+\ldots+\rho_{2 k} Q U I C_{t-k}+v_{2 t}\end{array}\right.$

\footnotetext{
${ }^{3}$ The setup of the tests are similar to those stated in the footnote of page 8 stated in the first step. We use drift and trend parameters in the auto-regressive regressions, and in order to find the truncation lag parameter we use the same default formula. For the quarterly data, the length of both series is 33 which is equivalent to the lag parameter equal to 3 for both $\mathrm{ADF}$ and the PP tests.
} 


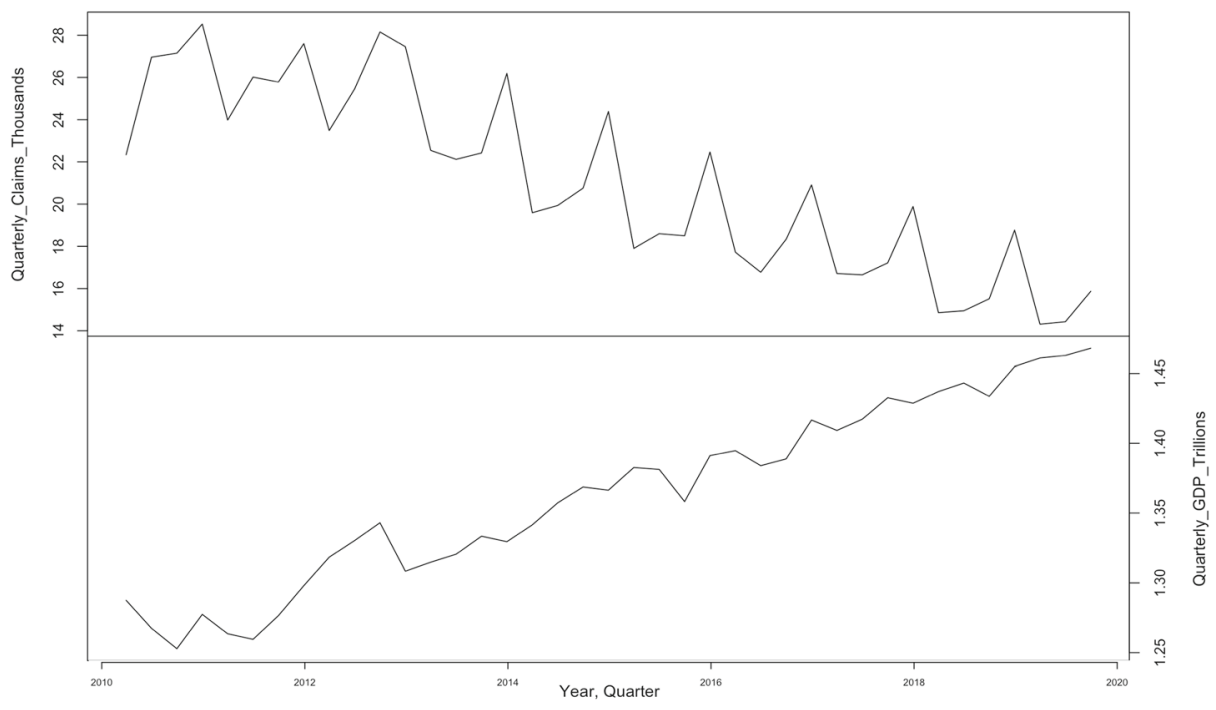

Fig.3 Quarterly Unemployment Insurance Claims and GDP: 2010-Q2 to 2019-Q4

where QUIC and GDP are Quarterly Unemployment Insurance Claims and quarterly GDP, $\alpha$ is the intercept, $\rho_{11, \ldots, 1 k}$ are the coefficients of lagged terms of QUIC in the QUIC equation, $\rho_{21, \ldots, 2 k}$ are the coefficients of lagged terms of QUIC in the GDP equation, $\theta_{11, \ldots, 1 k}$ are the coefficients of lagged terms of GDP in the QUIC equation, and $\theta_{21, \ldots, 2 k}$ are the coefficients of lagged terms of GDP in the GDP equation. $v_{1 t}$ and $v_{1 t}$ are the error terms. The optimal lag number in our quarterly analysis is measured to be 4 . The Impulse Response Function of GDP with respect to QUIC is provided in Fig. 4. After all, for one standard deviation shock in QUIC, GDP goes down by a mean of -3617.83 million dollars in response.

\section{Discussion}

The estimates of the effect of the outbreak on the economic output of the United States (and New York state) have mainly been provided by financial heavyweights, and government agencies. The predictions have been different and inconsistent over time, but all report a recession for 2020. Goldman Sachs, as an example, had estimated the US GDP to be dragged down to a record drop of $24 \%$ in the second quarter as of end of March (Goldman ); and in the middle of the second quarter sees $34 \%$ GDP contraction and $15 \%$ unemployment for the second quarter. Entering the second quarter, Deutsche Bank economists predicted the US economy would slump by $12.9 \%$ in the second quarter (Deutsche Bank ). Bank of America earlier in the quarter expected the economy to "collapse" in the second quarter, shrinking by $12 \%$ (Bank of America ). California-based PIMCO, one of the world's largest investment firms, predicts a $30 \%$ contraction in growth in the second quarter, measured at an annualized rate, which would likely be followed by two quarters of recovery. Atlanta Fed GDPNow estimates for the second quarter of 2020 stands at -34.9 (for the US).

More related to our research, New York Fed Staff Nowcast (a running estimate of New York's real GDP growth based on available data for the current quarter) for the second 
Table 2 Stationary and white noise tests

\begin{tabular}{llll}
\hline & PP Test & DF Test & ADF Test \\
\hline QUIC & $-30.282^{* * *}$ & $-7.0688^{* * *}$ & $-5.8099^{* * *}$ \\
& $(<0.01)$ & $(<0.01)$ & $(<0.01)$ \\
GDP & $-34.892^{* * *}$ & $-7.5449^{* * *}$ & $-3.4467^{* *}$ \\
& $(<0.01)$ & $(<0.01)$ & $(<0.05)$ \\
& & & Ljung-Box Test \\
QUIC & & & $21.891^{* *}$ \\
& & & $(0.01567)$ \\
GDP & & $25.922^{* * *}$ \\
& & & $(0.003846)$ \\
\hline
\end{tabular}

Note: QUIC and GDP are de-trended and de-seasoned. The number in parenthesis is the reported P-value of each statistic. The null hypothesis of the Phillips-Perron test and the Augmented Dickey-Fuller test is the series are non-stationary. The null hypothesis of the Ljung-Box test is the series are not auto-correlated.

${ }^{*} p<0.10,{ }^{* *} p<0.05,{ }^{* * *} p<0.01$

quarter of 2020 currently stands at $-19.3 \%$, explaining "positive surprises from retail sales, industrial production, capacity utilization, and housing data " to be the reason for a number lower than some other agencies.

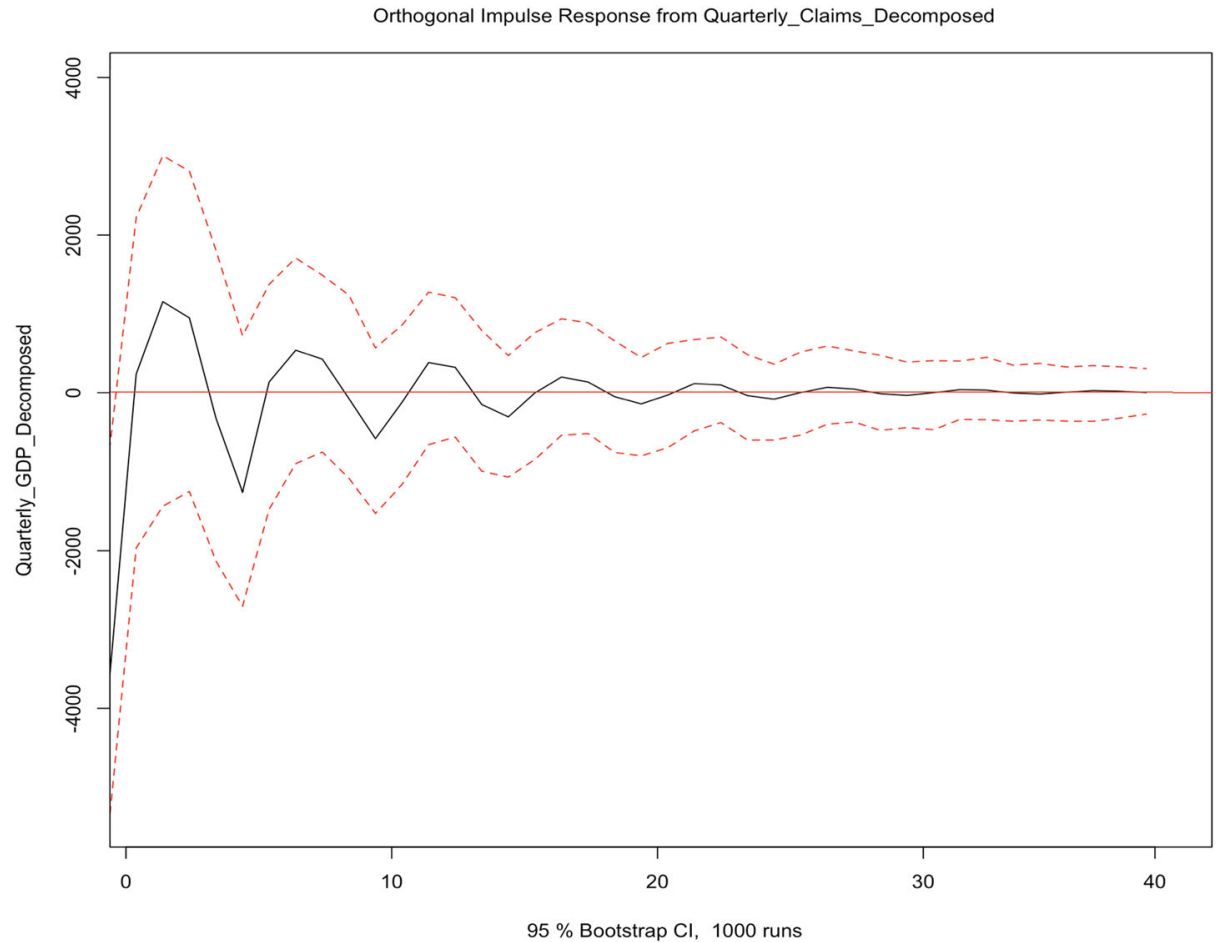

Fig. 4 Impulse Response Function: GDP in Response to a One Standard Deviation QUIC Shock 
From the first stage of our analysis, for the first quarter of 2020, the average Weekly Unemployment Insurance Claims shock is calculated to be 35,137 (with lower bound and upper bound of $[33,820.7,36,454.5])$ which is $4.32([4.15,4.48])$ times the standard deviation of the series (8141.9). For the second quarter,having the predictions from the first stage, the discrepancy between the "normal" values and the actual values, the average weekly shock is calculated to be $122,443.8$ ([118,205.0 , 126,682.6]) which is 15.0 ([14.5, 15.6]) times the standard deviation. From the second stage, for one standard deviation shock in the insurance claims, GDP goes down by a mean of -3617.83 million dollars in response. From our analysis this concludes in the annualized quarterly growth rate of real GDP to be $-4.147 \%$ for the first quarter $([-3.993,-4.299])$, and to be $-20.74([-19.79,-21.67])$ for the second quarter.

In our paper we utilize the available data, and our estimates are based solely on the mathematical results of the model, and capture the effects based on the standard internal dynamics of the model. As an example, our analysis does not go beyond the second quarter; or any unexpected second wave of the outbreak will change the dynamics.

It must also be noted that usually, the outbreak is an unusual shock on a macroeconomic system of variables. Generally, it is a recession in an economy that is followed and associated by a downfall in the employment rate. However, in this case, it can be said that the shock on the workforce will be a significant contributor to the inception and intensification of the expected recession. Therefore, we believe the VAR model in which variables are simultaneously effecting one another, under the current scenario performs well and is an appropriate model to estimate the behavior of the economic output. In the first stage also the strong co-variation of MTA ridership and WUIC strengthens forecasting abilities.

As mentioned earlier in the Introduction section, the formal reports on the extent and magnitude of the economic recession will not be fully clear and available until later on, while such information plays a critical role now that governments are setting strategies and policies to reopen economic activities. We believe working with the available data, studies that pay attention to the economic effects of the outbreak can be important during this period of time.

While we aim to measure the effect of the outbreak on New York's economic output; the state with one of the most restrict set of lock-down orders; we seek to be part of the big wave of research that is attempting to clarify the unique situation we are dealing with. We believe that even in the optimistic scenario of the end of all lock-downs soon, we are in the short-term phase of the analysis of economic costs of the outbreak. The US federal government (and governments around the globe) has (have) been continuously working on strategies such as stimulus packages and employment of different monetary policy tools to control and reduce the magnitude of the economic downfall, but the long term effects (including costs and benefits) of such policies remain to be studied in the future work. This experience will also renew our attention toward fields of studies focusing on disasters aggregate management and preparedness, demographic dynamics, and private preparedness and responses to the disasters (Kellenberg and Mobarak 2008; Maruta et al. 2020; Goeschl and Managi 2019; Pavel and Mozumder 2019; Owen and Noy 2019). Moreover, for the US specifically, we believe this can be the time to participate in (and pay specific attention to) the threads of studies focusing on the relationship between individual and household characteristics such as income and wealth percentile, gender, race, education and so on; and the unbalanced negative impacts of the economic downfall. An important question to ask simply is " who has been affected more?" (Alon et al. 2020; Baker et al. 2020; Adams-Prassl et al. 2020; Borjas 2020). 


\section{Conclusion}

This paper studied the effect of the COVID-19 outbreak on the economic output of New York, the epicenter of the outbreak in the US. We worked with a two-step VAR model to forecast and estimate the effect of the outbreak on New York's GDP for the first and second quarter of 2020. In the first step, we estimated the magnitude of the effect of COVID-19 on the workforce by working with the Weekly Unemployment Insurance Claims. Furthermore, the model also incorporated the total MTA ridership representing another dimension of economic activity. In the second step, we estimated the response of the Quarterly GDP with regard to the aggregate shock hitting the workforce, which we derived from the first step forecast. We estimated the reduction in the economic activity to drag down the annualized quarterly growth rate of real GDP to a drop of -20 to -22 percent compared to the normal circumstances for the second quarter of 2020 .

\section{References}

Adams-Prassl A, Boneva T, Golin M, Rauh C (2020) Inequality in the impact of the coronavirus shock: Evidence from real time surveys

Alon TM, Doepke M, Olmstead-Rumsey J, Tertilt M (2020) The impact of covid-19 on gender equality. Technical report, National Bureau of Economic Research

Baker SR, Farrokhnia RA, Meyer S, Pagel M, Yannelis C (2020) How does household spending respond to an epidemic? consumption during the 2020 covid-19 pandemic. Technical report, National Bureau of Economic Research

Bank of America BA Newsroom, April 2020. [Online]. Available from: https://newsroom.bankofamerica. $\mathrm{com} /$

Berisha E (2020) Tax cuts and" middle-class" workers. Econ Anal Policy 65:276-281

Borjas GJ (2020) Demographic determinants of testing incidence and covid-19 infections in new york city neighborhoods. Technical report, National Bureau of Economic Research

Bureau of Economic Analysis US Department of Commerce Data: Quarterly Real GDP Data by State, April 2020. [Online]. Available from: https://www.bea.gov/data

Centers for Disease Control and Prevention (CDC) (2020) Coronavirus disease 2019 (covid-19). Retrieved March 30, 2020 from https://www.cdc.gov/coronavirus/2019-ncov/cases-updates/cases-in-us.html

Davidson R, MacKinnon JG et al (2004) Econometric theory and methods, vol 5. Oxford University Press, New York

Deutsche Bank DB Newsroom, March 2020. [Online]. Available from: https://www.db.com/newsroom_news/ 2020/deutsche-bank-economists-forecast-severe-recession-due-to-covid-19-en-11507.htm

Giordano R, Momigliano S, Neri S, Perotti R (2007) The effects of fiscal policy in italy: Evidence from a var model. Eur J Polit Econ 23(3):707-733

Goeschl T, Managi S (2019) Public in-kind relief and private self-insurance. Econ Disas Clim Chang 3(1):321

Goldman S GS Research, April 2020. [Online]. Available from: https://www.goldmansachs.com/insights/ pages/gs-research/us-daily-20-mar-2020/report.pdf

AE Gorbalenya SC, Baker RS, Baric RJ, de Groot C, Drosten AA, Gulyaeva BL, Haagmans C, Lauber AM, Leontovich BW et al (2020) Neuman The species severe acute respiratory syndrome-related coronavirus: classifying 2019-ncov and naming it sars-cov-2. Nature Microbiology

Granger CWJ (1969) Investigating causal relations by econometric models and cross-spectral methods. Econometrica: journal of the Econometric Society, pp 424-438

Hatemi-J A (2014) Asymmetric generalized impulse responses with an application in finance. Econ Model 36:18-22

Kellenberg DK, Mobarak AM (2008) Does rising income increase or decrease damage risk from natural disasters? J Urban Econ 63(3):788-802

Mandel A, Veetil VP (2020) The economic cost of covid lockdowns: An out-of-equilibrium analysis. Available at SSRN 3588421

Maruta S, Kitsuki A, Managi S (2020) Perceived arrival time of disaster relief supplies matters for household preparedness for natural disasters. Economics of Disasters and Climate Change:1-20 
MTA MTA Fare Data, April 2020. [Online]. Available from: http://web.mta.info/developers/fare.html

Narayan PK, Narayan S, Prasad A (2008) A structural var analysis of electricity consumption and real gdp: Evidence from the g7 countries. Energy Policy 36(7):2765-2769

Owen S, Noy I (2019) Regressivity in public natural hazard insurance: a quantitative analysis of the New Zealand case. Econ Disas Clim Chang 3(3):235-255

Pavel T, Mozumder P (2019) Household preferences for managing coastal vulnerability State vs. federal adaptation fund. Econ Disas Clim Chang 3(3):281-304

Phillips PCB, Perron P (1988) Testing for a unit root in time series regression. Biometrika 75(2):335-346

Pichler A, Pangallo M, Maria del Rio-Chanona R, Lafond F, Doyne Farmer J (2020) Production networks and epidemic spreading: How to restart the uk economy? Production Networks and Epidemic Spreading: How to Restart the UK Economy

Said SE, Dickey DA (1984) Testing for unit roots in autoregressive-moving average models of unknown order. Biometrika 71(3):599-607

Aviral K et al (2011) Tiwari a structural var analysis of renewable energy consumption, real gdp and co2 emissions: evidence from india. Econ Bull 31(2):1793-1806

US Department of Labor Employment and Training Administration Data: Unemployment Insurance Weekly Claims Report, April 2020. [Online]. Available from: https://oui.doleta.gov/unemploy/claims_arch.asp

Wang Y, Fang Z, Gao W (2020) Covid-19's impact on China's economy based on data of spring festival travel rush. Available at SSRN: https://ssrn.com/abstract=3554638 or https://doi.org/10.2139/ssrn.3554638

World Health Organization (WHO) (2020) Coronavirus disease 2019 (covid-19): Situation report - 70. Retrieved March 30, 2020 from https://www.who.int/emergencies/diseases/novel-coronavirus-2019/ situation-reports/

Publisher's Note Springer Nature remains neutral with regard to jurisdictional claims in published maps and institutional affiliations. 